\title{
EL SECTOR AUDIOVISUAL COMO CONSUMO DE OCIO EN LA NUEVA ERA. LA TELEVISIÓN, UN MEDIO TODAVÍA EN AUGE
}

\author{
Noelia Araújo Vila ${ }^{1}$, \\ José Antonio Fraiz ${ }^{2}$, \\ Universidad de Vigo \\ naraujo@uvigo.es \\ jafraiz@uvigo.es
}

Material original autorizado para su primera publicación en la revista académica REDMARKA. Revista Digital de Marketing Aplicado https://doi.org/10.17979/redma.2011.01.07.4724

Recibido: 19 Septiembre 2011

Aceptado: 1 Diciembre 2011

\section{Resumen}

La Nueva Era o Sociedad del Ocio, se caracteriza por la aparición de un nuevo consumidor que premia el disfrutar de tiempo libre sobre el ganar más dinero a costa de trabajar más horas. Los productos o servicios más consumidos como parte de este tiempo libre tan apreciado, se encuentran dentro de la industria del ocio, y más concretamente, del sector audiovisual. Emergen nuevos productos o se adaptan a las nuevas tendencias los ya existentes, como la televisión, medio en el que se centra el presente artículo. La televisión, en pleno siglo XXI, sigue mostrando altos índices de audiencias a nivel mundial, a la vez que mantiene su objetivo originario, el informar y formar, a través de su amplia oferta diversificada. Por ello, a través de un estudio cualitativo, se pretende conocer cuál es su situación actual en el panorama nacional.

\footnotetext{
${ }^{1}$ Licenciada en Administración y Dirección de Empresas por la Universidad de Vigo y Doctoranda en Dirección y Planificación del Turismo de la Universidad de Vigo.

2 Profesor Titular del Departamento de Organización de Empresas y Marketing de la Universidad de Vigo. Doctor en Ciencias Económicas y Empresariales por la Universidad de Santiago de Compostela. 
Palabras clave: ocio, consumidor, televisión, audiovisual.

\begin{abstract}
AUDIOVISUAL SECTOR AS A CONSUMER OF LEISURE IN THE NEW ERA. TELEVISION, STILL BOOMING

The New Age or Leisure Society is characterized by the appearance of a new consumer rewards have free time on earning more money from working longer hours. The most consumed products or services as part of this highly valued free time, are within the entertainment industry, specifically, the audiovisual sector. Emerging new products or adapt to new and existing trends, such as television, the medium in which the focus of this article. Television, in the XXI century, continues to show high rates of audiences worldwide, while maintaining its original purpose, to inform and to train, through its wide range of diversified. Therefore, through a qualitative study, we try to know what the current situation is in the national scene.
\end{abstract}

Key words: leisure, consumer, television, audiovisual. 


\section{INTRODUCCIÓN}

Nos encontramos en la primera década de un nuevo siglo, siglo caracterizado por una nueva mentalidad que dista mucho de la del siglo anterior, donde el ganar más dinero a costa de trabajar más horas era el mayor incentivo, mientras que ahora el consumidor actual siente la necesidad no sólo de ganar más dinero, sino de contar con tiempo libre y modos de gastarlo (López, 2009:12). Así llegamos a lo que ya se denomina Nueva Era o Sociedad del Ocio, entendida no sólo como el tiempo disponible después del trabajo, sino como una promoción de nuevos valores (López, 2009:12), potenciada hoy en día por el mayor nivel adquisitivo y mayor esperanza de vida. Este sector en alza -1) medios de comunicación, 2) ocio y 3) entretenimiento-, que en el caso de la industria española se ha estimado que crecería una media anual del 7,9\% entre 2008 y 2012 y presenta más del 20\% del PIB, está estrechamente vinculado con un ámbito multidisciplinar que engloba cultura, deporte, recreación y turismo (Cuenca, 2008:34).

En esta nueva sociedad se ha producido un profundo cambio de valores, abriéndose paso el entretenimiento donde antes tenían mayor peso la religión o política. Por estos motivos, es justificable centrar el objeto de estudio de este artículo en esta industria tan al orden del día, dentro de la cual se analizarán los medios de comunicación -sector audiovisual-, los cuales día a día llegan a mayor número de usuarios, a la vez que repercuten favorablemente en otros sectores afines.

Para ello se partirá de una revisión de la literatura científica existente centrándonos en un medio audiovisual en concreto, la televisión, dadas sus destacadas cifras de consumo y proliferación de productos audiovisuales visionados a través de la misma (largometrajes y series de ficción en especial). A continuación se realizará una investigación sobre la situación actual y futura de este medio a través de la técnica cualitativa de la entrevista en profundidad, entrevistando para ello a 8 expertos a nivel nacional del sector audiovisual. 
Finalmente se procederá a discutir cuál es la realidad española del sector audiovisual en global y de la televisión como medio de estudio elegido, en función del marco teórico inicial y del estudio cualitativo realizado.

\section{EL CONSUMIDOR ACTUAL Y SU INTERÉS POR EL OCIO}

Ya a principios de siglo se inicia una cadena de cambios tanto en el sistema productivo como en el consumo que han ocasionado que los hábitos, tendencias y necesidades de los consumidores hayan evolucionado, originando un consumidor que se caracteriza por su exigencia y actividad. En lo que respecta al consumo del sector servicios, en ámbitos estrechamente vinculados con el consumo de ocio y entretenimiento, aparecen comportamientos como la realización de mayor número de viajes pero comprando menor número de billetes o el disfrute de mayor número de eventos culturales y artísticos, pero sin necesidad de ir más al teatro, cine o conciertos (Gershuny, 2005: 11). Han cambiado las formas de consumo, así como los lugares o medios de pago. Incluso a veces resulta difícil separar los diversos ámbitos -laboral, personal, ocio-, entrando así en una interrelación continua.

No podemos negar que la evolución de las tecnologías y la inmersión en la Era de la Información han favorecido esta actitud, especialmente con la aparición y rápida implantación de Internet, ya que el consumidor accede de un modo rápido a la información, haciéndolo conocedor de las características del producto o servicio que le interesa, así como sus derechos y prestaciones del mismo producto/servicio por parte de la competencia (López, 2009:12). Todo ello explica este nivel de exigencia y actividad, búsqueda continua de información e incluso aportación de comentarios en blogs, webs o foros, siendo el consumidor consciente de lo que compra y exigiendo recibir lo ofertado, o incluso algún valor añadido como puede ser garantía o servicio postventa.

Si nos trasladamos a Reino Unido, país europeo pionero en cuanto al inicio de la Revolución Industrial (s. XVIII-XIX) -y por lo tanto el primero en experimentar todos los cambios sociológicos, culturales y tecnológicos que ello ocasionó-, podemos analizar la evolución que sufrió en cuanto al disfrute del tiempo no 
destinado al trabajo, desde la década de 1960 a la década del 2000 (Tabla 2.1):

Tabla 2.1: Minutos al día dedicados a actividades en tiempo libre por mayores de 18 años en U.K.

\begin{tabular}{|l|l|l|l|}
\hline Concepto/año & $\mathbf{1 9 6 1}$ & $\mathbf{1 9 8 3}$ & $\mathbf{2 0 0 1}$ \\
\hline Dormir & 564 & 550 & 558 \\
\hline Alimentarse & 94 & 82 & 65 \\
\hline Hogar e hijos & 213 & 268 & 244 \\
\hline Compras, tiempo libre fuera de casa & 87 & 121 & 136 \\
\hline TOTAL & 958 & 1021 & 1003 \\
\hline
\end{tabular}

Fuente: elaboración propia a partir de Gershuny 2005:15

Observamos que aunque el total de tiempo ajeno al trabajo no ha incrementado espectacularmente (de 958 a 1003 minutos), sí lo ha hecho la forma de consumir este tiempo, pasando el tiempo dedicado a estar fuera de casa de 87 a 136 minutos (un aumento del 56,32\%).

Volviendo al caso español, si analizamos la evolución de gasto en los hogares españoles desde finales de esta década (2006 a 2008), el gasto en ocio, espectáculos y cultura (grupo 9) representa un $6,89 \%$ del gasto total, continuando la tendencia a ello en aumento (en 2008 un 9,79\% más que en 2006) (Tabla 2.2).

Tabla 2.2: Gasto de los hogares españoles (euros) 2006-2008

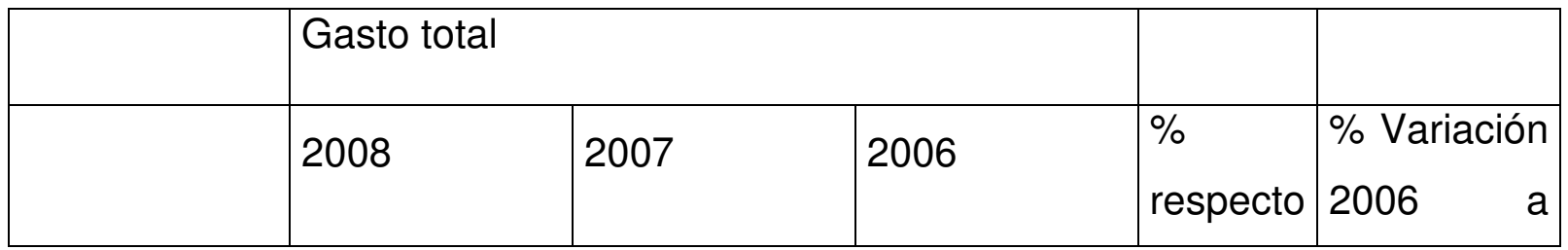




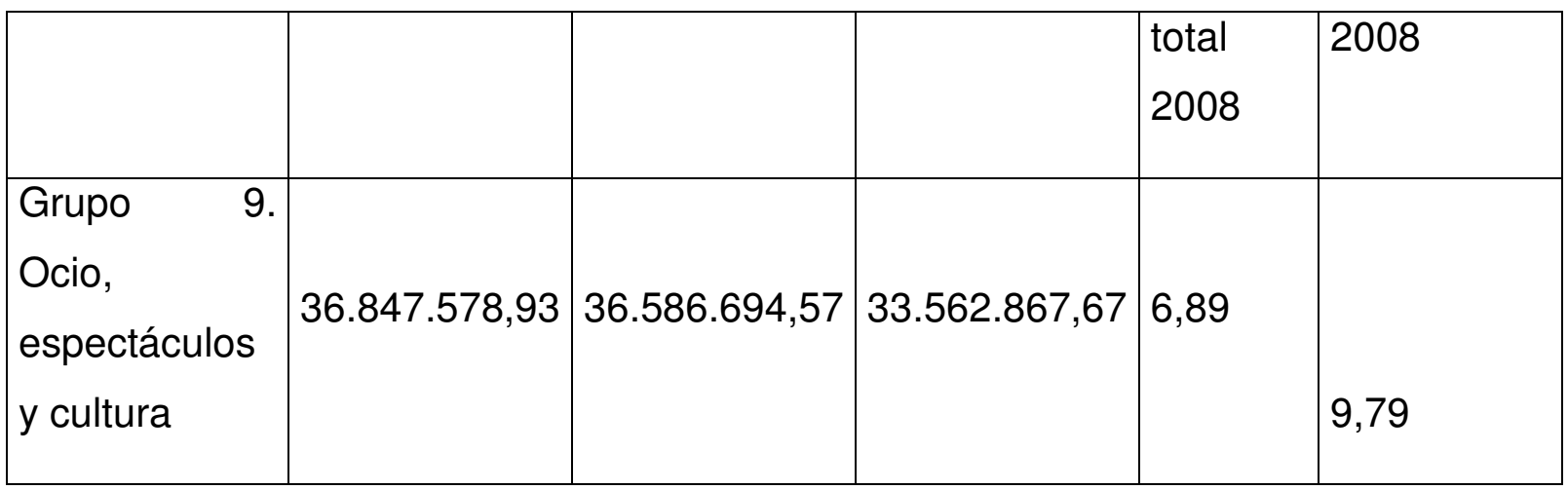

Fuente: elaboración propia a partir de INE, Encuesta de Presupuestos Familiares, base (2006)

Remitiéndonos a datos más recientes, en el caso de la industria española del ocio, se ha estimado que ésta crecería una media anual del 7,9\% entre 2008 y 2012 (Pricewaterhouse Coopers, 2008), superando el crecimiento vivido hasta el momento y presentando actualmente más del $20 \%$ del PIB.

Los últimos datos arrojados por el INE, no hacen más que respaldar los argumentos ya mencionados, mostrando cifras que defienden el interés actual en España por las actividades vinculadas con el ocio, en especial los servicios audiovisuales, el turismo y actividades recreativas, culturales y deportivas. Podemos analizar los datos tanto desde el punto de vista de la oferta o de la demanda. Desde el punto de vista de la demanda, cada vez son más los minutos diarios que se dedican a ocio, sea ver televisión (una media de 2 horas y 52 minutos y medio), escuchar música (1 hora y 41 minutos) u otras actividades de ocio y tiempo libre (2 horas y 24,5 minutos) -INE, 2006 -. Si lo analizamos desde el punto de vista de la oferta, el número de empresas vinculadas al ocio aumenta, llegando en 2006 a la cifra de 70.000 (INE, 2010).

A la hora de analizar el consumidor actual de la Nueva Era o Sociedad del Ocio, debemos hacer hincapié en los adolescentes (14-19 años), ya que por un lado serán en los próximos años los potenciales clientes de nuestra sociedad y ahora mismo los de alto poder adquisitivo «un perfil de consumidor muy apetecible, manejable y maleable que sólo se entiende a sí mismo si está al día sujeto al dictado del novum» (Borefull, 2003: 111), siendo por otro lado, este 
novum el interés que manifiestan en esta industria o sector vinculada a las nuevas tecnologías.

El concepto adolescente ha sufrido una evolución, pasando de ser un niño que se preparaba para la madurez y un futuro prometedor ante una emergente sociedad industrial y urbana de los siglos XVIII-XIX (Bofarull, 2005:116) al adolescente actual, cuya infancia ya ha sido marcada por la incorporación de la mujer al trabajo, a la presencia de las TICs en sus vidas, a un espacio propio, menor número de hermanos o hijo único, acceso a la educación y mayor poder adquisitivo. Se trata de un adolescente informado y preparado,

El adolescente de la década actual vive en una nueva industria del ocio y revolución digital, por lo que dedica gran parte de su tiempo libre al disfrute de estas nuevas tendencias. Tales tendencias las podemos clasificar, según Borafull (2005), en dos categorías:

Mass media: Televisión (deporte, programación adulta, series adolescentes), cine, DVDs, vídeos, radio, periódicos deportivos, revistas de videojuegos, de consolas, de música o Internet.

Self media: nuevas tecnologías de la información y comunicación, medios de contacto más directo, interactividad y bidireccionales, características que poco a poco están haciendo que ganen mayor peso e interés frente a los anteriores.

Estas nuevas preferencias en cuanto a consumo de ocio en los adolescentes, evidencian la importancia que las TICs están tomando, llegando algunos autores a hablar ya de «generación @» 0 «screenagers» (del inglés teenager + screen), entendido como el adolescente que pasa muchas horas delante de una pantalla -televisión, monitor de PC, móvil o incluso auriculares- (Borafull, 2005:120).

La televisión no ha dejado de consumirse, sino que están emergiendo nuevos modos de consumo, como la televisión digital o consumo de otros medios de un modo paralelo al consumo de la misma, como el siguiente gráfico de Mediascope Europe 2010 evidencia (Gráfico 2.1). En España, datos del 2009, 
se indica que el $21 \%$ de los usuarios de Internet lo han usado de modo simultáneo a la televisión.

Gráfico 2.1: Consumo de TV y otros medios paralelamente (año 2008)

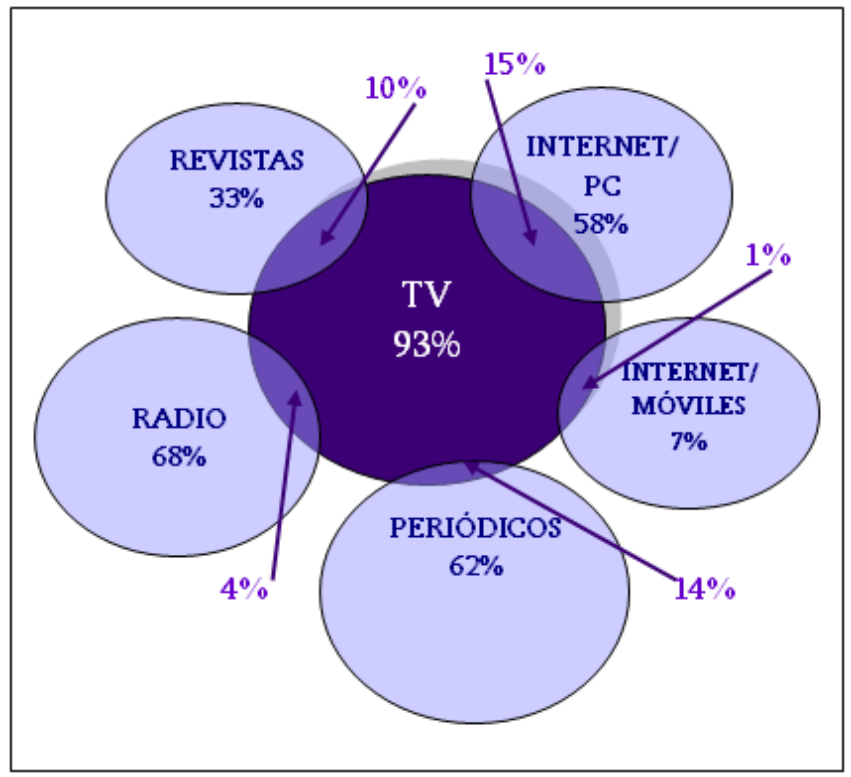

Fuente: Elaboración propia a partir de Mediascope Europe (2010:23)

Tal y como se ha expuesto hasta ahora, estamos ante un consumidor (adolescente) preparado e informado, que asegura no dejarse influir por la publicidad, aunque otros estudios evidencian lo contrario (Teens, 2010).

Este segmento de la sociedad que mueve sólo en España 8.000 millones de euros anuales (Teens, 2010) se está adaptando a los cambios citados en la introducción, para los cuales nuevas formas de pago son Internet y en un futuro próximo el propio móvil (dinero electrónico), cambios demográficos como la carencia de hermanos y cambios educativos tales como el acceso a una educación de mayor calidad.

Se trata de una generación que llegará a la edad adulta más tarde, ya que se incorporarán al mundo laboral una vez finalizados los estudios (muy pocos compaginarán ambas cosas) y seguirán viviendo en casa de sus padres a los 
30-35 años, por lo que seguirán manteniendo el perfil de teens próximos a los 30 años.

En lo que respecta al tiempo de ocio, éste será prácticamente consumido en su totalidad a través de nuevas tecnologías, donde estarán interconectados a través de 50.000 millones de dispositivos multiusos (Internet, móviles, redes sociales, blogs, prensa online), prediciéndose una media de conexión a tales medios de 30 horas semanales.

\section{LOS MEDIOS AUDIOVISUALES Y SU CONSUMO}

En este siglo los cambios tanto en el sector audiovisual como en el perfil del consumidor de este sector han sido notables. A la vez que el consumidor ha cambiado sus prácticas, hábitos y preferencias (R. Campo, Martínez y Juanatey, 2005), el sector audiovisual también ha evolucionado a través de nuevas estrategias y modos de comercialización.

El sector audiovisual ha diversificado su oferta ofreciendo mayor variedad de géneros que puedan llegar a un mayor número de consumidores (la tendencia actual es un consumo individualizado), y el interés de los consumidores ha ido en aumento hacia el género de ficción, no sólo en cine, sino en especial al ofertado en las series (R. Campo, Martínez y Juanatey, 2005: 7), ya no sólo en televisión, sino a través de otros medios.

Dos siglos después de la aparición del cine de manos de los hermanos Lumière, nos encontramos ante un sector que ha presentado una gran expansión, ampliándose a campos que van más allá del cine, como la televisión, vídeos y todo el mundo multimedia en el que hoy vivimos (Internet, videojuegos o la televisión interactiva, entre otros). Se trata de un sector con gran peso en la economía actual, ya no sólo por sí mismo y la creciente demanda que ha despertado y sigue despertando, sino también por su alta y directa vinculación con otros sectores como pueden ser las tecnologías, informática o telecomunicaciones, cuya expansión incentiva el desarrollo de dichos sectores, y viceversa, llegando así a lograr importantes sinergias (Martí y Muñoz, 2001:124). 
Dentro de la industria del ocio, en la cual se puede englobar este sector-como ya hemos visto en el epígrafe anterior-, el peso que tiene es notable, presentando una cifra de negocio de 23.354.849 miles de euros en España servicios audiovisuales, cinematográficos, radio y televisión-, y mantiene ocupadas a 154.334 personas (INE, 30 septiembre 2006).

Pero, ¿qué entendemos por audiovisual? Según la RAE «lo que se refiere conjuntamente al oído y a la vista, o los emplea a la vez. Se dice especialmente de métodos didácticos que se valen de grabaciones acústicas acompañadas de imágenes ópticas». Con tal definición se manifiesta la necesaria conexión o simultaneidad del oído y la vista para que un medio tenga la consideración de audiovisual, de ahí que siendo estrictos, la radio no formaría parte de este sector. A pesar de ello, la mayor parte de autores y estudios la consideran como tal, entendiendo dentro del término audiovisual el uso de imágenes y/o audio, concretamente, "la inclusión de imágenes fijas como las pinturas y fotografías, imágenes en movimiento tales como películas, televisión y vídeo, y grabaciones de sonido de la música, la voz, u otros sonidos, o como un componente de mover los documentos de la imagen» (Turner, 2010:84).

Si vamos más allá del término, y buscamos ya la definición de sector audiovisual, limitándonos a la definición de la Comisión Europea, cap. 27 (1988), se entiende éste como «la producción y distribución de películas cinematográficas, las actividades de radio y televisión, y los estudios de grabación». Con tal definición de finales de la década de 1980, en este caso los que no estarían incluidos dentro de este sector, serían los servicios multimedia, pero es evidente la proliferación que éstos han tenido desde 1980 al año actual (2011). Por lo que en la última década, diversos autores que han trabajado en este campo, sí que los han considerado como parte de esta industria, pudiendo definir este sector a día de hoy como «el conjunto heterogéneo de mercados caracterizado por participar directa o indirectamente en la provisión y recepción simultánea de sonido e imágenes en movimiento» (Martí y Muñoz, 2001:126). Partiendo de esta definición, el sector audiovisual, desde el punto de vista del producto, englobaría los siguientes subsectores: cine, televisión, vídeo/DVD y multimedia, quedando de nuevo excluida la radio y grabaciones musicales (y nuevos formatos como los podcasts de audio), por lo que tras la controversia 
que se presenta de unos autores a otros se añadirá este quinto subsector a los cuatro ya citados en el presente estudio, intentando abarcar el mayor campo del sector en cuestión, el audiovisual.

\section{LA TELEVISIÓN}

\subsection{EVOLUCIÓN Y CONSUMO ACTUAL}

Aunque como se acaba de ver, el sector audiovisual abarca diversos campos o subsectores, nos centramos en uno de ellos que llama la atención por las destacadas cifras que maneja y por ser testigo de las transformaciones sociales y tecnológicas que la sociedad ha sufrido (Ortiz, 2005:1): la televisión.

Así la televisión se ha convertido en un fenómeno sociológico, cultural, político e incluso psicopedagógico, perdurando desde su aparición y llegando a ser uno de los inventos de la Humanidad con más transcendencia e impacto en la misma (Mayugo, 2005:1).

La televisión ha dejado de ser exclusivamente un evento social en que toda la familia veía un mismo programa junta, a que en cada hogar existan varias televisiones y cada uno vea en diferentes habitaciones el programa o serie más acorde a sus gustos (Bjur, 2010). En 1999 todavía el 45\% de los telespectadores veían la televisión de modo conjunto, pero en 2008 esta cifra descendió al 37\%.

Ciertos eventos todavía siguen atrayendo a un consumo masivo (partidos de fútbol o ciertos festivales - Eurovisión-), pero actualmente con respecto a la década pasada existen mayor número de actores, géneros, competencia, programas, canales de televisión y modos de acceso al entretenimiento, lo que ha hecho que el consumo de este sector se vuelva individualizado.

Además, esta amplia oferta de canales de televisión, programas, formatos, etc., hacen prácticamente imposible utilizar como temas de conversación la programación televisiva. $Y$ aún así, los consumidores de este medio todavía comparten opiniones, pero estas discusiones tienen lugar habitualmente en foros o grupos especializados en Internet, principalmente cuando de series se trata (Bjur, 2010). 
El objetivo de la televisión es claro, tanto en el momento de su aparición como en la actualidad: entretener, informar y formar (Mayugo, 2005:2). Pero desde su aparición al momento actual la evolución ha sido significativa, ya que hasta entrada la década del 2000 el hablar de televisión significaba referirse a todo aquello que en ella se visionaba: comentar programas, series, películas, personajes entre otros, y a día de hoy tales consideraciones siguen estando presentes, pero a ello se añaden dos notables transformaciones (Ortiz, 2005:2):

La aparición de la televisión digital, la cual utiliza nuevos envíos de señales, redes de fibra óptica y nuevos soportes -Internet y telefonía móvil-. Un factor también relevante es la inclusión de la denominación «de pago», ya que hasta ahora ésta era concebida como un servicio público financiado por las emisiones de publicidad. Ante tal panorama el consumidor tiene que ser más selectivo ante una mucha más amplia oferta de productos, además de que no puede comprar todo ni dispone de tiempo para consumirlo todo.

Derivada de la anterior, del concepto de pago, aparece una televisión especializada y centrada en lo que cada consumidor busca mercado de venta y compra de programas, generalistas y/o mediáticos. Si un consumidor busca un programa especializado de cierto tema, éste tendrá que abonarse a un canal específico.

La evolución de la televisión, la podemos dividir, partiendo del modelo estadounidense -pionero de nuevo al igual que pasó con el cine- en tres eras (Lotz, 2009: 50):

Network era: desde principios de 1950 a la década de 1980.

Multi-channel transition: desde mitad de la década de 1980 a la década de 1990.

Post-network era: desde principios de este siglo.

Con la aparición de la televisión en USA en los años 50 se consiguió transportar el mundo exterior a los hogares (McCarthy, 2001). La oferta televisiva era muy básica y limitada, solamente tres canales con horarios 
limitados, y las opciones de elección del consumidor eran escasas. Aún así, la televisión pasó a formar parte del mobiliario de todos los hogares, alrededor de la cual se hacía vida familiar (Lotz, 2005: 51). Llegaron los años 80 y con ellos la época de transición, marcada por la aparición de nuevas tecnologías como el mando a distancia, la cinta de vídeo o la televisión por cable, teniendo así los televidentes mayor oferta y estilos de programación. Tuvo que llegar la década del 2000 para que la televisión sufriese los cambios más significativos y trascendentales, sonando palabras como «crisis» o «fin» ante el desarrollo de nuevos dispositivos que permitían ver el programa deseado en el momento deseado (Lotz, 2005:52,53). Tal predicción fatalista no llegó a ser real, sino que tras una adaptación oferta/demanda ésta sobrevivió y lo sigue haciendo, siendo la televisión uno de los medios a los que los consumidores más tiempo de su ocio dedican. Uno de los avances que más ayudó a ello fue la aparición de la televisión digital, con su consecuente mejora en la calidad de emisión así como proliferación de contenidos.

En el caso de Europa, la evolución fue similar a la estadounidense. En la mayoría de los países que la forman, tras la aparición de este invento se inició la emisión de 2-3 canales en su mayoría de carácter público, los cuales a día de hoy siguen teniendo un importante peso. Ejemplos de ello son Alemania, donde la fragmentación de las audiencias es un hecho y aún así dos canales públicos siguieron teniendo un importante peso, con la cuarta parte del mercado hasta mediados de la década de 2000 (ARD y ZDF); Francia, donde hasta 2005 el operador público (France 2, France 3 y France 5) era uno de los líderes del mercado; Reino Unido, con 3 canales públicos: BBC1, BBC2 y Channel 4 o España, con dos canales nacionales en abierto, TVE y La 2, y doce canales públicos regionales en abierto, de los cuales hasta 2005 junto FORTA sumaban el 43 \% de la cuota de mercado (Camáñez, 2005: 2-5).

Centrándonos en el caso de España, hasta entrada la década de 1990, el mercado estaba liderado por la televisión pública. Por ello el mercado de la televisión estaba monopolizada por el estado, los contenidos controlados por éste, y de igual modo las pautas en cuanto a su modo de financiación, totalmente publicitaria entre 1983 y 1993, año a partir del cual empezó a recibir pequeñas subvenciones. La aparición de la televisión privada en 1990 no hizo 
más que acabar con su monopolio y entrar con ello en un periodo de déficit (Bustamante y Monzoncillo, 1999).

Fue a principios de esta década (1989-1990) cuando empezaron a competir televisión pública y privada, buscando captar tanto audiencia como publicidad, siendo por el momento la única cadena de pago Canal Plus. Aparece así la «neotelevisión» abriéndose paso ante la «paleotelevisión», (Cortés, 1999). La llegada de los canales privados supuso una mayor comercialización de contenidos y medición de las audiencias (Artero, Herrero y Sánchez: 2005:8485).

A día de hoy, en España es evidente que la televisión no ha muerto, y ante la diversidad actual de canales que oferta la TDT, los españoles pasan más tiempo delante de la misma haciendo que ésta siga en auge, 226 minutos diarios de media en 2009 -1 minuto menos que 2008, 3 minutos más que 2007 y 9 más que 2006 (EGEDA, 2009) (Tabla 4.2)-, llegando a niveles máximos de 311 minutos diarios para los telespectadores mayores de 65 años y 145 minutos para el colectivo comprendido entre 13 y 24 años (EGEDA, 2010).

La aparición de la TDT no ha hecho más que ampliar la oferta televisiva, revelando las últimas cifras de audiencia española (2010) que las cadenas temáticas ya empiezan a ser una amenaza para las generalistas. Aunque TVE1 sigue siendo líder con el 15,7\% de la cuota (tabla 4.1), la cadena digital Clan TVE igualó a La 2 en el mes de abril de 2010, llegando 3,1\% de la cuota de pantalla, siendo su programa más seguido «Bob Esponja» - alcanzando el millón de espectadores en «prime time» el 15 de abril de 2010- (Kantar Media, 2010).

Tabla 4.1: Ranking audiencias de canales de televisión en España 2010

\begin{tabular}{|l|l|l|l|}
\hline Puesto & Cadena & $\begin{array}{l}\% \text { cuota de } \\
\text { mercado }\end{array}$ & $\begin{array}{l}\text { variación } \\
\text { respecto año } \\
\text { anterior }\end{array}$ \\
\hline 1 & La 1 & 15,7 & $-0,9$ \\
\hline
\end{tabular}




\begin{tabular}{|l|l|l|l|}
\hline 2 & Tele5 & 14,6 & $+0,1$ \\
\hline 3 & Autonómicas & 11,6 & $-1,1$ \\
\hline 4 & Antena3 & 11,5 & $-0,7$ \\
\hline 5 & La Sexta & 7,5 & $+0,4$ \\
\hline 6 & Cuatro & 6,9 & - \\
\hline
\end{tabular}

Fuente: elaboración propia a partir de Kantar Media (2010)

Dentro del ranking mundial de consumo televisivo, España ha ascendido del vigésimo quinto puesto del año 2008 al vigésimo segundo en el año 2009, considerándose una posición medio-alta, ya que supera en 36 minutos la media mundial de consumo diario: de 184 minutos en 2005 a 192 minutos en 2009 (EGEDA, 2010). La superan países como Serbia (único país con más de 300 minutos diarios de consumo), Egipto (286), Macedonia (286), Armenia (280) y Estados Unidos (280) (cinco primeros puestos del ranking) (EGEDA, 2010). Desde que se mide la audiencia a través de SOFRES (desde 1992), en 2010 se ha llegado a esta cifra récord.

En lo que respecta a la implantación de la TDT, ésta ya ha llegado a un 73,8\% de los hogares españoles (AIMC, 2010). El consumo medio diario de TDT está en 132 minutos/día, y en los hogares que ya disponen de TDT en 169 minutos diarios (AIMC, 2010).

Tabla 4.2: Consumo de televisión en España 2006-2009 (minutos/día)

\begin{tabular}{|l|l|}
\hline AÑO & CONSUMO (MIN/DÍA) \\
\hline 2006 & 217 \\
\hline 2007 & 223 \\
\hline 2008 & 227 \\
\hline 2009 & 226 \\
\hline
\end{tabular}

REDMARKA UIMA-Universidad de A Coruña - CIECID

Año IV, Número 7, (2011), pp. 33-60 
Fuente: elaboración propia a partir de Egeda (Panorama Audiovisual 2008/2009)

Respecto a la programación que hace al consumidor pasar tal tiempo de su ocio delante del televisor, la ficción lidera las preferencias a escala mundial, ascendiendo al $45 \%$ de emisiones en 2008. Nos referimos al cine y a las series, aumentando considerablemente tanto la emisión de largometrajes en televisión, llegando en 2008 a 14.542 -4.825 más que en 2006-, como de series -39.496 emitidas en 2008, un 46,36\% más que en 2006- (EGEDA, 2009) y 41.099 en 2009, un 4\% más que en 2008 (EGEDA, 2010) -Tabla 4.3-. La distribución del tiempo de emisión, el 36,3\% fue destinado a series de ficción, seguido del 3\% destinado a largometrajes, $17,2 \%$ a animación, el 15\% a documentales y el $28,5 \%$ a otros programas. Tales cifras no hacen más que reflejar la importancia que las series tienen hoy en día y el notable peso que han tomado dentro de las preferencias del consumidor, de ahí que en el presente estudio se dedique un epígrafe a ello.

Tabla 4.3: Evolución emisión series y largometrajes en televisión 2006-2009

\begin{tabular}{|l|l|l|l|l|}
\hline AÑO & $\begin{array}{l}\text { Emisión } \\
\text { series }\end{array}$ & $\begin{array}{l}\text { Incremento } \\
\text { respecto año } \\
\text { anterior }\end{array}$ & $\begin{array}{l}\text { Emisión } \\
\text { largometrajes }\end{array}$ & $\begin{array}{l}\text { Incremento } \\
\text { respecto año } \\
\text { anterior }\end{array}$ \\
\hline $\mathbf{2 0 0 6}$ & 26.986 & - & 9.717 & - \\
\hline $\mathbf{2 0 0 7}$ & 36.094 & $33,75 \%$ & 12.782 & $31,54 \%$ \\
\hline $\mathbf{2 0 0 8}$ & 39.496 & $9,42 \%$ & 14.542 & $13,77 \%$ \\
\hline $\mathbf{2 0 0 9}$ & 41.099 & $4,05 \%$ & 15.259 & $4,93 \%$ \\
\hline
\end{tabular}

Fuente: elaboración propia a partir de Egeda (Panorama Audiovisual 2008/2009)

\subsection{METODOLOGÍA DE LA INVESTIGACIÓN}


La recogida de información primaria se ha realizado a través de la técnica cualitativa de la entrevista en profundidad. El número total de entrevistas realizadas fue de 8 , a agentes tanto del sector público como privado, y la fecha de realización comprendió el periodo abril-julio de 2011. Los agentes entrevistados pertenecen al sector audiovisual, representando a las comunidades españolas con mayor actividad en este sector y presencia de clusters audiovisuales reconocidos: Andalucía, Cataluña, Islas Baleres, Madrid y Galicia. Se han seleccionado gestores de Film Commissions y representantes de productoras privadas y consultoras vinculadas con el sector (Tabla 4.4).

Tabla 4.4: Muestra de individuos entrevistados

\begin{tabular}{|c|c|c|c|c|}
\hline $\mathbf{N}$ & Entrevistado & Profesión & Región & Sector \\
\hline 1 & $\begin{array}{ll}\text { Dña. } & \text { Carlota } \\
\text { Guerrero } & \end{array}$ & $\begin{array}{l}\text { Coordinadora Catalunya } \\
\text { Film Commission }\end{array}$ & Cataluña & \\
\hline 2 & D. Pedro Barbadillo & $\begin{array}{l}\text { Director Mallorca Film } \\
\text { Commission }\end{array}$ & Illes Balears & \\
\hline 3 & D. Carlos Rosado & $\begin{array}{l}\text { Presidente Andalucía Film } \\
\text { Commission }\end{array}$ & Andalucía & \\
\hline 4 & Dña. Piluca Querol & $\begin{array}{l}\text { Directora Andalucía Film } \\
\text { Commission }\end{array}$ & Andalucía & \\
\hline 5 & D. Juan Luis Tejedor & Gerente HT Consultores & Andalucía & \\
\hline 6 & Dña. María Liaño & Directora de Producción & Galicia & \\
\hline 7 & D. Jose Luis Escolar & Productora independiente & Madrid & \\
\hline 8 & $\begin{array}{l}\text { D. Jose Antonio } \\
\text { Corredoira }\end{array}$ & $\begin{array}{l}\text { Director Fundación TIC, } \\
\text { Lugo }\end{array}$ & Galicia & 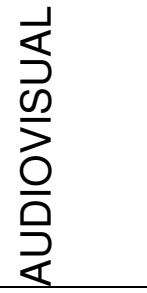 \\
\hline
\end{tabular}


Fuente: elaboración propia

El tipo de entrevista elegida fue la semi-estructurada, de tal modo que los entrevistados respondiesen a una serie de preguntas según un guión establecido y tuviesen libertad para profundizar en aquellos aspectos en los que son expertos y tienen una mayor opinión.

El objetivo que se persigue con dichas entrevistas es conocer cuáles son los productos audiovisuales más consumidos en el panorama nacional actual, así como el medio preferido para ello, pudiendo comprobar así si la televisión está todavía en auge, tal y como se presupone tras la revisión teórica.

\subsection{RESULTADOS DE LA INVESTIGACIÓN}

Tras realizar las 8 entrevistas ya mencionadas en el apartado anterior, en función de las respuestas obtenidas de los 8 agentes vinculados de modo directo con el sector audiovisual, se exponen a continuación los resultados de las 5 preguntas que han generado la información más relevante para la presente investigación (Tabla 4.5):

Tabla 4.5: Preguntas con información más relevante

1.-Al hablar de sector audiovisual, ¿cuáles cree según su experiencia 0 estudios realizados en su comunidad, que son los productos que más consumen los espectadores?

2- En lo que respecta a las series audiovisuales, de nuevo según su experiencia o estudios realizados ¿cuál cree que es el género más consumido?

3.- ¿Qué fuentes de información cree que suele consultar un espectador para empezar a ver una serie o para realizar comentarios sobre la misma?

4.- Actualmente, ¿cuál cree que es el soporte mayoritario de consumo de series audiovisuales?

5.- En un futuro próximo, ¿cuál cree que será el soporto mayoritario de 
consumo de series audiovisuales?

Tabla 4.6: Pregunta 1

Al hablar de sector audiovisual, ¿cuáles cree según su experiencia o estudios realizados en su comunidad, que son los productos que más consumen los espectadores?

\section{Entrevistado Respuesta}

\begin{tabular}{|c|c|}
\hline 1 & Informativos, documentales y series audiovisuales. \\
\hline 2 & $\begin{array}{l}\text { Series audiovisuales, deportes y programas de ocio y } \\
\text { entretenimiento. }\end{array}$ \\
\hline 3 & Largometrajes, series audiovisuales y reallities. \\
\hline 4 & $\begin{array}{l}\text { Largometrajes, series audiovisuales y programas de ocio y } \\
\text { entretenimiento. }\end{array}$ \\
\hline 5 & Largometrajes, deportes y programas del corazón. \\
\hline 6 & Series audiovisuales, informativos y programas del corazón. \\
\hline 7 & Series audiovisuales, deportes e informativos. \\
\hline 8 & Series audiovisuales, deportes y programas del corazón. \\
\hline
\end{tabular}

En lo que respecta a los productos audiovisuales más consumidos actualmente (Tabla 4.6), existe una clara predilección por las series audiovisuales, mencionadas por 7 de los 8 entrevistados. Podemos incluir también como productos más consumidos del panorama actual tras las series audiovisuales, los deportes, informativos, largometrajes y programas del corazón.

Tabla 4.7: Pregunta 2

En lo que respecta a las series audiovisuales, de nuevo según su experiencia o 
estudios realizados ¿cuál cree que es el género más consumido?

\section{Entrevistado Respuesta}

\begin{tabular}{|l|l|}
\hline 1 & Comedia, ficción y serial televisivo. \\
\hline 2 & Dramedia, historia/biográfica, sitcom. \\
\hline 3 & Comedia, serial televisivo y sitcom. \\
\hline 4 & Comedia, ficción y sitcom. \\
\hline 5 & Comedia, policíaca y acción. \\
\hline 6 & Comedia, drama y policíaca. \\
\hline 7 & Comedia, ficción y acción. \\
\hline 8 &
\end{tabular}

El género más consumido en las series audiovisuales tampoco presenta lugar a dudas: la comedia, ya que así lo creen 7 de los 8 expertos entrevistados (Tabla 4.7). Le siguen en segundo lugar los sitcom, o comedias de situación, que no son más que series cómicas con 2 o 3 tramas por episodio, un número limitado de personajes y no más de dos decorados polivalentes (López, 2009), siguiendo por tanto dentro de una temática cómica. Ejemplos de sitcom son en España la conocida serie 7 vidas o a nivel internacional The Big Bang Theory.

Por último, podríamos situar en tercer lugar las series de acción, desmarcándonos ya de la temática cómica.

Tabla 4.8: Pregunta 3

¿Qué fuentes de información cree que suele consultar un espectador para empezar a ver una serie o para realizar comentarios sobre la misma?

\section{Entrevistado Respuesta}

\begin{tabular}{l|l}
\hline 1 & Familia/amigos, redes sociales y publicidad en televisión.
\end{tabular} 


\begin{tabular}{|c|c|}
\hline 2 & $\begin{array}{l}\text { Familia/amigos, publicidad en televisión, ver al azar al } \\
\text { programación que hay en televisión. }\end{array}$ \\
\hline 3 & $\begin{array}{l}\text { Publicidad en TV, radio/prensa, ver al azar al programación que } \\
\text { hay en televisión. }\end{array}$ \\
\hline 4 & Familia/amigos, publicidad en televisión y redes sociales. \\
\hline 5 & $\begin{array}{l}\text { Familia/amigos, radio/prensa y guías de programación } \\
\text { televisiva. }\end{array}$ \\
\hline 6 & Internet (blogs, foros), redes sociales y publicidad en televisión. \\
\hline 7 & Redes sociales, publicidad en televisión y radio/prensa. \\
\hline 8 & $\begin{array}{l}\text { Familia/amigos, publicidad en televisión y ver al azar al } \\
\text { programación que hay en televisión. }\end{array}$ \\
\hline
\end{tabular}

Las fuentes de información preferidas por los espectadores para comentar sus series favoritas o informarse para empezar a ver una nueva serie, son la publicidad en la propia televisión y los amigos y familiares, grupos de referencia más influyentes (Tabla 4.8). Los expertos entrevistados hablan de estos dos medios, sin poder establecer una clara predominación de uno sobre el otro. Lo que descartan la mayoría son medios tradicionales como las guías de televisión, prácticamente no utilizadas a día de hoy.

Tabla 4.9: Pregunta 4

Actualmente, ¿cuál cree que es el soporte mayoritario de consumo de series audiovisuales?

\section{Entrevistado Respuesta}

\begin{tabular}{|l|l|}
\hline 1 & Televisión/TDT y PC vía internet. \\
\hline 2 & Televisión/TDT y PC vía internet. \\
\hline 3 & Televisión/TDT y PC vía internet. \\
\hline
\end{tabular}




\begin{tabular}{|c|c|}
\hline 4 & $\begin{array}{l}\text { Televisión/TDT, PC vía internet y en la propia página web de la } \\
\text { cadena televisiva. }\end{array}$ \\
\hline 5 & Televisión/TDT. \\
\hline 6 & Televisión/TDT y PC vía internet. \\
\hline 7 & Televisión/TDT, PC vía internet y televisión de pago. \\
\hline 8 & Televisión/TDT y PC vía internet. \\
\hline
\end{tabular}

En cuanto al soporte de consumo de series, no hay ninguna duda por parte de los expertos, coincidiendo todos ellos en que la televisión TDT y el visionado en PC de series a través de internet, ya sea en la propia página web de la serie o a través de otras páginas webs, son el presente (Tabla 4.9).

Tabla 4.10: Pregunta 5

En un futuro próximo, ¿cuál cree que será el soporte mayoritario de consumo de series audiovisuales?

\section{Entrevistado Respuesta}

\begin{tabular}{|l|l|}
\hline 1 & Televisión/TDT y PC vía internet. \\
\hline 2 & Televisión/TDT y PC vía internet. \\
\hline 3 & Televisión/TDT y PC vía internet. \\
\hline 4 & $\begin{array}{l}\text { Televisión/TDT, PC vía internet y en la propia página web de la } \\
\text { cadena televisiva. }\end{array}$ \\
\hline 5 & $\begin{array}{l}\text { Televisión/TDT, televisión de pago y en la propia página web de } \\
\text { la cadena televisiva. }\end{array}$ \\
\hline 6 & PC vía internet y móvil/smartphone. \\
\hline 7 & Televisión/TDT, PC vía internet y televisión de pago. \\
\hline 8 & Televisión/TDT, PC vía internet y en la propia página web de la \\
\hline
\end{tabular}


cadena televisiva.

Si replanteamos la cuestión anterior, preguntando por un futuro próximo en lugar del presente, prácticamente no obtenemos variaciones, creyendo los expertos que por ahora la televisión TDT e internet seguirán siendo los soportes más utilizados por los espectadores (Tabla 4.10). Incluso alguno de los entrevistados, haciendo una previsión a mayor plazo, cree en la aceptación que llegarán a tener móviles o smartphones como soportes de consumo audiovisual, ampliándose una vez más el uso de dichos dispositivos.

\section{DISCUSIÓN Y CONCLUSIONES}

El sector servicios, y especialmente la industria del ocio y del entretenimiento, son los grandes protagonistas del siglo XX y XXI. Al consumidor actual ya no le atrae en mayor medida el poder ganar un poco más de dinero, sino el disponer de tiempo libre para poder gastarlo y disfrutarlo (López, 2009:12). Se producen por tanto una serie de cambios en los hábitos y necesidades de los consumidores, entre los que despiertan especial interés el ocio, cultura y espectáculos. Nace por tanto la que podemos denominar Nueva Era o Sociedad del Ocio, en la que si indagamos un poco más, representa un gran peso el sector audiovisual, suponiendo sólo en España una cifra de negocio superior a los 23.000 .000 miles de euros.

Dentro del sector audiovisual, se incluyen subsectores como la televisión, el cine, la radio o el mundo multimedia, destacando a día de hoy algunos en mayor medida que otros. Dentro de los más demandados, llegando a convertirse en fenómeno sociológico, cultural, político e incluso psicopedagógico, está la televisión. Ésta, desde su aparición, persigue un doble objetivo: informar y formar (Mayugo, 2005:2), objetivo que de algún modo sigue todavía presente a pesar de presentarse algo difuso en ciertos casos. La televisión ha sufrido cambios significativos, siendo uno de los últimos la aparición de la televisión digital, por lo que el consumidor ante la variada oferta puede ser mucho más selectivo. 
Estamos ante un medio que ha sabido evolucionar desde sus inicios, llegando actualmente a diversificar su oferta -distintos programas, formatos y canales-, adaptándose a los diferentes segmentos poblacionales y manteniéndose todavía dentro de los medios más consumidos: una media mundial de consumo diario de 36 minutos, superando los 200 minutos diarios en diversos países (Estados Unidos, Egipto o Armenia) y llegando en algunos incluso a los 300, como en Serbia (EGEDA, 2010). Un medio que en España se mantiene a día de hoy como el soporte preferido por los espectadores para consumo de productos audiovisuales, en especial de las series de ficción, producto audiovisual más consumido. Incluso a la hora de informarse para consumir nuevos productos audiovisuales, los espectadores se guían por la publicidad vista en televisión, convirtiéndose ésta en la herramienta promocional por excelencia. Así lo reflejan los expertos nacionales vinculados con este campo, apostando por la televisión TDT a día de hoy y en un futuro próximo. 


\section{REFERENCIAS}

\subsection{BIBLIOGRAFÍA}

ARTERO, J.P. (2005). Monopolio, oligopolio y competencia en los últimos quince años de televisión en España, Sphera Pública, № 005, págs. 8398.

BJUR (2010). Cada vez se ve más la tele solo que en compañía, La flecha, diario de ciencia y tecnología [consultado online, laflecha.net, 27/01/2010]

BORAFULL, I. (2003). Adolescentes eternos y ocio mediático, Comunicar, Revista Científica de Comunicación y Educación, №21, págs. 109-113.

BORAFULL, I. (2005). Ocio en los nuevos medios de comunicación, Revista Juventud, no 68, págs. 116-127.

BUSTAMANTE, E. (1999). España: la producción audiovisual en el umbral digital, Revista de Economía de la Cultura, №2.

CAMÁÑEZ, G. C. (2005). Televisión en Europa: análisis y comparativa de las principales cadenas públicas en seis países, Comunicar: Revista científica iberoamericana de comunicación y educación, ํo 25.

Comisión de las Comunidades Europeas (1988). Los medios de comunicación audiovisual en el single mercado europeo. Luxemburgo: Oficina de Publicaciones Oficiales de las Comunidades Europea

CORTÉS, J. A. (1999). La estrategia de la seducción. La programación en la neotelevisión. EUNSA. Pamplona.

CREAFUTUR (2010). Estudio Teens 2010.

CUENCA, M. (2008). La del siglo XXI es una Sociedad del Ocio, Periódico de Bilbao, 11 de enero de 2008, pág.34.

EGEDA (2010). Panorama audiovisual 2009-2010.

EUROPEAN INTERACTIVE ADVERTISING ASSOCIATION (2010): Mediascope Europe 2010. Media Comsuption Study. 
GERSHUNY, J (2005). What do we do in Post-industrial Society? The nature of work and leisure time in the $21^{\text {st }}$ Century, ISER, Institute for Social \& Economic Research, ํo 7.

HERRERO, M. y DIEGO, P. (2009). Series familiares de televisión: concepto, producción y exportación. El caso de Médico de Familia, RLCS, Revista Latina de Comunicación Social, 64, págs. 238-247.

HUDSON, S. y BRENT, J. R. (2006). Promoting Destinations via Film Tourism: An Empirical Indentification of Supporting Marketing Initiatives, Journal of Travel Research, vol. 44, págs. 387-396.

KANTAR MEDIA (2010). Boletín Mensual de Audiencia de TV. Enero 2010. Febrero 2010. Abril 2010. Mayo 2010. Junio 2010.

LÓPEZ, C. (2009). La nueva era del consumidor, Profesiones, № 117, págs. 12-13.

LOTZ, A. (2009). What is U.S. Television now? The Annals of the American Academy of Political and Social Science, 꾸 625, págs. 49-59.

McCARTHY, A. (2001). Ambient television. Duke University Press. United States of America.

MARTÍ, F. P. y MUÑOZ, C. (2001). Economía del cine y del sector audiovisual en España, ICE, Economía de la Cultura, № 792, págs. 124-138.

MAYUGO, C. (2005). Hacia otro modelo de sistema televisivo en la era de la comunicación global, Comunicar, Revista Científica de Comunicación y Educación, 25, págs. 91-99.

ORTIZ, M. A. (2005). Televisión, globalización y cambio social”, Comunicar: Revista científica iberoamericana de comunicación y educación, no 25.

R. CAMPO, L., MARTíNEZ, V. A. y JUANATEY, O. (2005). Evolución en las preferencias de los consumidores de productos audiovisuales, Comunicar: Revista científica iberoamericana de comunicación y educación, nำ 25, 2. 
R. CAMPO, L. (2010). Tesis Doctoral El cine como estrategia promocional y de definición de producto turístico. Evaluación de su impacto en la imagen percibida del destino. Universidad de Vigo.

TURNER, J.M. (2010). From ABC to http: The Effervescent Evolution of Indexing for Audiovisual Materials, Cataloging \& Classification Quarterly, 48:1, págs. 83-93.

\subsection{REFERENCIAS ELECTRÓNICAS}

- $\quad$ http://bcdash.bigchampagne.com/

- $\quad$ www.cinefania.com [consultado el 24/05/2010]

- $\quad$ http://www.elpais.com/articulo/internet/Imparable/fuga/audiencia/televisiv

a/Internet/elpeputec/20090828elpepunet_1/Tes [consultado el 5/03/2010]

- $\quad$ http://www.formulatv.com/

- $\quad$ http://www.geca.es

- $\quad$ www.hollywoodreporter.com

- www.ine.es

- $\quad$ http://www.kantarmedia.es/

- $\quad$ laflecha.net, diario de Ciencia y Tecnología [consultado el 27/01/2010].

- $\quad$ http://ivefeed.hollywoodreporter.com/2010/05/lost-finale-highestratedepisode-in-two-years.html, [consultado el 25/05/2010]

- $\quad$ www.movieandgo.com

- $\quad$ http://www.pergaminovirtual.com.ar/definicion/Podcast.html [consultado el 19/04/2010]

- $\quad$ www.plus.es/festivaldeseries [consultado el 25/05/2010]

- $\quad$ www.pwc.com 
- www.rae.es

- $\quad$ www.themoviemap.com

- $\quad$ http://torrentfreak.com/

- $\quad$ 20minutos.es [consultado el 24/05/2010]

Para citar este artículo:

Araújo Vila, Noelia - Fraiz, José Antonio (15-12-2011). EL SECTOR AUDIOVISUAL COMO CONSUMO DE OCIO EN LA NUEVA ERA. LA TELEVISIÓN, UN MEDIO TODAVÍA EN AUGE.

REDMARKA - CIECID - Unidad de Investigación en Marketing AplicadoUniversidad de A Coruña

Año IV, Número 7, V1, pp.33-60

ISSN 1852-2300

URL del Documento : cienciared.com.ar/ra/doc.php? $n=1595$

URL de la Revista : cienciared.com.ar/ra/revista. php? wid=39 